\title{
Silêncio e (meta)linguagem em "Fale com ela"
}

\author{
Renata Farias de Felippe ${ }^{* *}$
}

\begin{abstract}
Michel Chion nos diz que o grito no cinema é principalmente feminino e que suas possibilidades expressivas são inúmeras. É sempre um grito de mulher, quem sabe porque haja um sabor sádico ou porque o gozo feminino seja interdito ao homem. O grito do homem é um grito de poder, um grito de Tarzan, demarcando seu território fálico. ${ }^{1}$
\end{abstract}

Não há gritos em "Fale com ela". Nem femininos, nem de nenhuma espécie. Aliás no filme, contrariando o clichê, as mulheres pouco falam, e o uso do tempo verbal no imperativo presente no título denuncia este silêncio.

Em "Fale com ela" predomina, literalmente, a voz masculina, mas no filme, os homens também não gritam, ao contrário. Na película, o tom de voz dos personagens é o mesmo de Caetano Veloso na releitura de Cucurucucu paloma, o que contraria a idéia de que esse "diretor de mulheres seja responsável por deixar à beira de um ataque de nervos também os homens". ${ }^{2}$

\footnotetext{
" Crítica do filme "Fale com ela" dirigido por Pedro Almodóvar, 2002

*** Professora substituta da Universidade Federal do Rio Grande, Rio Grande-RS, Brasil.renata.felippe@terra.com.br

1 HaOuli, Janete El. A voz de Almodóvar. In: CAÑIZAL, Eduardo Peñuela (org). Urdidura de sigilos. São Paulo, Anablume, 1996. p.89

2 Melo, Andréa Bezerro de. A presença feminina no cinema de Almodóvar. Ibidem. p.235.
} 
Silêncio e (meta)linguagem...

Ao enfatizar, no filme, personagens femininas silenciadas, Pedro Almodóvar subverte não só o estereótipo relativo à verborragia feminina, como também rompe com os clichês do próprio estilo. Várias de suas personagens podem ser consideradas mulheres, digamos, "alteradas", como Pepi, Glória, Pepa, Kika, Andréa Caracortada, Leocádia. No que diz respeito a sua reduzida produção literária, nesta, também encontramos figuras peculiares como todas as personagens de Fogo nas entranhas. Porém, na fase considerada "madura" da filmografia almodovariana posterior a Kika (1993) - a presença de mulheres perturbadas parece menor, ainda que em Fale com ela Lydia seja uma personagem passional e conflituosa. Tal redução, possivelmente, seja resultante da tentativa de renovação do diretor, uma tentativa de escapar à repetição. Segundo Affonso Beato:

Alguns anos depois de ter feito 'Kika', ele (Pedro Almodóvar) entrou em conflito. Com 'Kika' ele chegou ao fim de um movimento estético que estava muito cenográfico, muito alegórico, e que já estava muito longe da realidade. [...] As pessoas não gostavam de 'Kika', nem ele estava gostando mais. ${ }^{3}$

Sendo assim, a partir de A flor do meu segredo (1995), as mudanças estéticas e temáticas tornam-se evidentes. No que diz respeito às imagens, a fotografia de seus filmes passa a enfatizar o amarelo, o marrom, o vermelho e a estética kitsch é diluída. Quanto aos personagens, os conflitos destes tornam-se profundos. A caricatura, a paródia e o caráter anárquico, tornam-se menos evidentes.

O cinema de Pedro Almodóvar renova-se não apenas devido a um processo natural ou por sua própria necessidade de auto-superação, mas porque sua obra, "reproduzindo os

3 apud BARTUCCI, Giovana. Almodóvar ou o desejo como universo. Revista de leitura, $n^{\circ}$. 7, São Paulo, Imprensa Oficial, julho de 2003, p.15. 
mecanismos do próprio desejo, aniquila com a possibilidade de fixação de padrões e modelos". 4

Se a temática do desejo é uma constante no diretor, e este é despertado por uma infinidade de agentes e tem infinitos desdobramentos, apontando para a diversidade de situações, por outro lado, é inegável que a produção do cineasta possui incidências. Esta, atenta contra todo o tipo de ordem sexual estabelecida a partir da dicotomia masculino/feminino, possui uma profunda ligação com figuras marginais, bem como utiliza-se da função metalingüística para explicitar as emoções $e$ as características dos personagens. Esta última característica, em especial, é a temática do presente trabalho $e$ o fato que motivou a escolha de Fale com ela como foco de análise, uma vez que, a meu ver, este é o filme de Almodóvar que mais se utiliza de recursos metalingüísticos.

$\mathrm{Na}$ obra do diretor manchego a sexualidade não está reduzida a uma diferença binária (masculino/feminino). Em Fale com ela certas características relativizam as supostas diferenças entre os sexos, pois identificamos nos personagens elementos que a convenção ditou como inerentes ao sexo oposto. Lydia é uma toureira, portanto, mulher cuja escolha profissional a associa à idéia de virilidade. No entanto, esta se mostra uma figura passional e emotiva, atributos convencionalmente interditados aos homens. Marco, o namorado de Lydia, se emociona ao assistir Pina Bausch e ao ouvir Caetano Veloso, rompendo com o pressuposto de que a insensibilidade seria uma característica masculina. Por outro lado, a razão o impede de se comunicar com a namorada em coma, o que remete à dificuldade de expressar sentimentos atribuída aos homens. Benigno, o enfermeiro apaixonado por Alicia, esta também em coma, cuida de sua amada com um zelo quase maternal, do mesmo modo que

4 SiLva. Wilson da. No limiar do desejo. In: CAÑIZAL, E. P. Urdidura de sigilos... Op. cit., p.63. 
Silêncio e (meta)linguagem...

havia cuidado da própria mãe. Porém, ao violar Alicia, Benigno assume o lado mais violento e sombrio da masculinidade.

No que diz respeito à metalinguagem, esta pode ser vista, de uma maneira generalizada, como uma linguagem que serve para descrever outra linguagem ou qualquer sistema de significação. Elemento que se faz presente na obra do diretor espanhol tanto em sua fase de formação quanto de confirmação, a metalinguagem, em Ata-me (1986), por exemplo, se faz através da inserção de um filme de terror dentro da narrativa, película que representaria o desejo de Máximo (o personagem-diretor) em submeter Marina. Em Tudo sobre minha mãe, a personagem Huma Rojo encena Um bonde chamado desejo, despertando as lembranças de Manuela que, no passado, teria vivido a mesma situação de Estela, personagem do texto de Tenessee Williams. Sendo assim, a função metalingüística em Almodóvar "está em seus filmes explicitamente para se submeter à grande função almodovariana, a função emotiva". 5

Em Fale com ela, três linguagens distintas se inserem na narrativa cinematográfica: a dança (espetáculos Caffe Muller e Fogo), a música (interpretação de Caetano Veloso) e a tauromaquia. Temos também como exemplo de metalinguagem o filme mudo Amante minguante, dentro do filme em questão. A intensa utilização do mecanismo metalingüístico na película, além de contribuir para a função emotiva, constitui um recurso que permite uma caracterização mais completa dos personagens, sendo que em certos momentos, a metalinguagen funciona como uma espécie de agente premonitório, referente a fatos e ações que ainda estão por vir.

\section{Caffe Mueller}

Nas primeiras cenas de Fale com ela, Benigno e Marco estão assistindo ao espetáculo de dança Caffe Mueller, com Pina

\footnotetext{
5 http://www.geocities.com/contracampo/tudosobreminhamae.html
} 
Bausch. Neste, duas bailarinas de camisola dançam de olhos fechados, cercadas por cadeiras, sendo que um homem afasta os obstáculos do caminho de uma delas, enquanto a outra choca-se contra a parede. Na platéia, Marco se emociona com o espetáculo, chamando a atenção de Benigno. Neste momento, temos dois receptores que reagem de forma distinta à apresentação. Um deles, Benigno, mostra-se atento $e$ concentrado; o outro,Marco,surge visivelmente emocionado, a ponto de não conter as lágrimas. Fatos futuros serão capazes de justificar tais reações, bem como a presença do ballet no filme.

Benigno (que é enfermeiro) assiste atentamente à apresentação para depois descrevê-la a Alicia, uma jovem em coma, sob seus cuidados, e por quem o personagem é apaixonado. Assim como o homem que, no espetáculo, afasta as cadeiras do caminho de uma das dançarinas privada da visão, Benigno também será os olhos de Alicia e a figura que, até certo ponto, prezará por seu bem-estar. Caffe Mueller também remete ao microuniverso de Alicia, personagem que, antes do coma, era bailarina.

Marco, ao comover-se com a apresentação, demonstra sua sensibilidade aguçada e, sob certo aspecto, sua coragem. Vestígios de uma visão sexista, ainda presentes em nossa sociedade, vetam aos homens o direito de expor seus sentimentos, o que faz do personagem uma figura que contraria o estereótipo de masculinidade ainda vigente. Além de propiciar a exposição de características do personagem, a apresentação de dança (recurso metalingüístico), de certa forma, antecipa fatos futuros: Marco irá apaixonar-se por Lydia (representada pela segunda bailarina), mulher que também ficará em coma, e, nesta ocasião, conhecerá Benigno e Alicia. Assim como uma das dançarinas, Lydia estará sozinha em seu coma, já que Marco mostrar-se-á incapaz de comunicar-se com ela. Desta incapacidade resultará o título do filme e o uso do verbo no imperativo. É Benigno quem aconselha Marco a "falar com ela" (Lydia). 
Silêncio e (meta)linguagem...

No filme, o primeiro uso da metalinguagem, portanto, tem o objetivo de indicar situações futuras, assumindo um sentido de antecipação aos fatos.

\section{Salomé contra o touro}

A tauromaquia é, possivelmente, a manifestação mais reconhecida como inerente à cultura espanhola. $\mathrm{O}$ ato de tourear é uma das atividades na qual há uma incipiente participação feminina, uma vez que dominar o touro e penetrá-lo repetidas vezes com a lança são atos que remetem à virilidade. No entanto, é inevitável associar tal atividade também à feminilidade, pois a capacidade de seduzir, atrair o animal com o uso da capa vermelha (espécie de véu) são atos que remetem, convencionalmente, às estratégias femininas de conquista.

Afinal de contas, o toureiro controla o animal através do véu (a capa vermelha). $\mathrm{O}$ movimento da capa fascina a vítima, que, confusa, se torna um alvo fácil à penetração da espada e das lanças. ${ }^{6}$

Sob tal perspectiva, pode-se ver o ato de tourear como ação que articula elementos masculinos e femininos, o que atribui ao ato um caráter híbrido, capaz de aproximar o mais viril toureiro da figura sedutora de Salomé. ${ }^{7}$ Tal relação com a personagem bíblica torna-se ainda mais estreita quando temos uma toureira. Lydia desafia a estrutura patriarcal ao colocar-se, a princípio, como agente do sacrifício, e não como vítima. É ela quem penetra o touro, causando incômodo aos seus colegas de profissão por executar um ato encarado como viril. Se considerarmos as estratégias de sedução como próprias à feminilidade, o fato de uma mulher tourear não seria inusitado.

${ }^{6}$ Melo, André da Mota Bezerra de. A presença feminina no cinema de Almodóvar. In: CAÑIZAL, E. P. Urdidura de sigilos ... Op. cit., p.234

7 Curiosamente, Salomé (1978) é o título de um dos curtas de Almodóvar. 
Assim como a figura do toureiro/a a personalidade de Lydia também articula elementos tradicionalmente associados aos dois sexos. Ao mesmo tempo em que é corajosa e fria, atributos supostamente masculinos e essenciais à profissão, mostra-se perturbada quando abandonada pelo ex-amante. O perfil híbrido da personagem fica explícito quando, na cena da tourada, Lydia enfrenta e vence o touro (ato associado à virilidade) ao som de Elis Regina, cuja voz interpreta a devoção de uma mulher ao seu bem-amado, o que remete ao sentimentalismo atribuído ao sexo feminino. Talvez a fusão de características tradicionalmente vistas como masculinas e/ou femininas seja a responsável pelo caráter conflituoso e contraditório da personagem. Ao vencer o touro diante do ex-amante, também toureiro, Lydia se vinga do abandono e tenta mostrar-se no controle de seus sentimentos. Por outro lado, a trilha sonora representa o seu mais recôndito desejo: o de expressar o seu amor e o seu devotamento àquele que a abandonou.

Lydia enfrenta touros, mas teme cobras, e quando finalmente reata com o homem que ama, se oferece ao sacrifício ao deixar-se vencer pelo touro (representação do patriarcado). O ato contraditório aponta para várias leituras, embora eu destaque duas. A personagem pode ter-se entregado à morte por saber que sua relação com o Niño de Valênsia estaria fadada ao fracasso. A tentativa de suicídio da personagem também pode remeter a um traço relevante na obra do diretor: "Almodóvar leva ao extremo a imolação do corpo feminino para salientar a rígida tipificação sexual da cultura patriarcal. Trata-se, portanto, de uma atitude totalmente conceitual". ${ }^{8}$

O sacrifício voluntário da personagem representa a renúncia e a crítica à sociedade patriarcal. O gesto de Lydia é contraditório como a sua própria natureza: ao mesmo tempo em que desiste de lutar contra o patriarcalismo e se nega a passar por mágoas futuras, demonstrando sua fragilidade, jamais se coloca na

8 Melo, A. M. B. A presença feminina... Op. cit., p.255. 
Silêncio e (meta)linguagem...

condição de vítima. Lydia tem um final trágico porque assim o deseja.

\section{O canto sutil ou os doces latinos}

Durante aproximadamente três minutos do filme, Caetano Veloso canta a tristeza de um homem abandonado em sua versão para Cucurucucu Paloma, tradicional música mexicana. Ao assistir a performance, o personagem Marco emociona-se mais uma vez, $e$ a metalinguagem funciona como um suporte para a função emotiva, novamente.

A emotividade de seu caráter também relativiza as diferenças entre os gêneros, uma vez que o choro $e$ a exposição de sentimentos é considerada uma fraqueza que vai de encontro ao conceito de virilidade. Tão importante quanto a análise da utilização da metalinguagem, um fato anterior à performance de Caetano Veloso deve ser considerado.

Logo após conhecer Lydia, Marco a deixa em casa. É neste momento que a personagem encontra uma cobra e fica em pânico, demonstrando uma de suas fraquezas. Marco, por sua vez, se vê obrigado a liquidar o animal e, ao fazê-lo, chora. Ao contrário de Lydia, Marco não sente medo do animal, mas matálo o faz recordar uma situação semelhante e um antigo amor. No momento em que o personagem "salva" Lydia, esta passa a interessar-se por ele. Esta é uma passagem importante, pois além de expor a sensibilidade de Marco, é uma alegoria ao relacionamento entre este e Lydia.

$\mathrm{O}$ ato de matar a cobra remete a duas leituras complementares e, estranhamente, contraditórias. Se ao matar o animal o personagem mostra-se corajoso e defensor da "mocinha" em perigo, por outro lado, este estaria sacrificando um símbolo que remete à masculinidade, como se o mesmo tivesse de atenuar certas características associadas à virilidade para conquistar Lydia. Marco conquista-a por mostrar-se duplamente corajoso: por "salvá-la", tomando a atitude que se espera de um "homem", $e$ 
por mostrar-se fragilizado diante de uma mulher, ambigüidade que remete ao perfil do próprio personagem que se sensibiliza ao ouvir uma canção, mas cuja racionalidade o impede de comunicar-se com a namorada em coma.

A participação de Caetano Veloso no filme é, portanto, o recurso metalingüístico que evidencia a porção emotiva do personagem, e não a sua totalidade. A escolha do cantor brasileiro não é casual: além da amizade deste com o diretor, a sutileza de sua voz e de sua interpretação representam a sensibilidade de Marco. A própria letra da canção tem uma função quase que profética: em um determinado momento, Lydia abandonará Marco, e este também sentir-se-á frágil e sozinho como o homem de quem fala a música. A escolha de um cantor brasileiro também pode ser uma espécie de homenagem. Assim como Marco, que é argentino, Caetano Veloso também é latino-americano e interpreta uma conhecida música mexicana. A presença da argentina Cecília Roth, que também assiste à performance, parece reforçar esta suposta apologia. Sendo assim, a utilização da metalinguagem, neste caso, além de ser um suporte à função emotiva e de, sutilmente, indicar uma situação posterior, também remete a uma outra cultura, referência que projeta o filme para além do contexto espanhol, este, sinteticamente representado por Lydia.

\section{Amante minguante}

Em Fale com ela, os atos contraditórios dos personagens podem ser derivados da fusão entre os atributos que, supostamente, delimitariam os gêneros masculino e feminino. Esta também é uma das justificativas possíveis para a violência de Benigno contra Alicia. Ao violar a personagem, Benigno, que até então dedicara-se à sua amada devotadamente, o que remete ao cuidado maternal, assume o lado obscuro e agressivo de sua masculinidade. 
Silêncio e (meta)linguagem...

Assim como Lydia exerce uma profissão predominantemente masculina, a profissão de enfermeiro exercida por Benigno é, principalmente, executada pelas mulheres. Além de enfermeiro, o personagem exerce também as funções de cabeleireiro e esteticista, pois, antes mesmo de conhecer Alicia, cuidava de sua própria mãe, o que representa uma inversão das funções tradicionais. O personagem, cujos atributos o aproximam da idéia de maternidade e, conseqüentemente, de feminilidade, tem a sua masculinidade latente despertada através de um recurso metalingüístico.

No caso de Benigno, a metalinguagem funciona como um mecanismo de transgressão do personagem consigo, bem como com a própria lei. Ao assistir o filme mudo Amante minguante, o personagem tem o seu desejo de possuir Alicia despertado, desejo este anteriormente compensado pelo simples prazer de cuidá-la. Sylvia Loeb define a natureza de Benigno, antes da violação, como um estado paradisíaco de indiferenciação sexual.

Benigno dedica-se de corpo e alma à adoração e aos cuidados daquela mulher viva/morta. Mais do que isso, Benigno realiza um dos sonhos mais secretos da mulher: o de ter um homem que se dedique inteiramente a ela. ${ }^{9}$

No entanto, após o contato com o filme - no qual o protagonista torna-se minúsculo, realizando uma das fantasias sexuais primordiais do homem, que seria a de ser totalmente engolido pela mulher - Benigno tem definido o seu papel sexual. Segundo S. Loeb:

Almodóvar, grande artista que é, ilustra magistralmente e com muito humor, a fantasia sexual fundante do homem: o de ser totalmente engolido, engolfado pela Grande Vagina da Mulher. Fascinação e medo desse imenso buraco, negro,

9 LOEB, Silvia. O impossivel entre homens e mulheres www.gradiva.com.br/ impossivel.htm, 29-08-2004. 
misterioso (...) que pode aterrorizar o homem para o resto de sua vida.

Ao despertar a sua masculinidade, Benigno reivindica o direito de exercê-la e de ter a sua dedicação compensada. O personagem, inclusive, revela a sua intenção de casar-se com Alicia. No entanto, no filme, a obediência à lei do desejo tem um preço: Benigno é preso, acusado de violar uma mulher sem defesas, contrariando o significado de seu próprio nome.

A metalinguagem, portanto, é usada com a intenção de trazer à tona fantasias do inconsciente mais profundo do personagem, sendo também a responsável pelo desencadeamento de uma série de fatos que tem seu desfecho com o triste fim do mesmo.

\section{Fogo, Alicia e o final feliz}

Dos personagens de Fale com ela, Alicia é a única que não apresenta qualquer contradição, exatamente por passar maior parte do filme atada ao silêncio. Esta, também é a personagem cuja mudez torna-a ainda mais misteriosa, uma vez que esta comunica-se com o espectador através de uma linguagem que exclui gestos e palavras.

As aparições da personagem são cercadas por uma aura sedutora. A nudez e a beleza da atriz são exploradas, e esta é colocada em uma posição propícia à contemplação, não só quando dança graciosamente, atraindo o olhar de Benigno da janela de casa, mas também quando aparece pela primeira vez a Marco nua e envolvida em lençóis. São exatamente a imobilidade, o silêncio e a beleza de Alicia os elementos que colocam-na em uma posição ideal à observação, atraindo os olhares masculinos do filme. De acordo com Silvia Loeb, "essa linda mulher em coma", encanta por realizar "um dos sonhos mais secretos do homem: o de ter uma mulher absolutamente à sua mercê" ${ }^{10}$

${ }^{10}$ LOEB, S. O impossível... Op. cit. 
Silêncio e (meta)linguagem...

O espetáculo de dança Fogo, que marca o reencontro de Marco e Alicia, em um determinado momento, sintetiza a presença deste filme. No palco, uma mulher sensual passa pelas mãos de vários homens e seu corpo está inteiramente entregue às mãos dos bailarinos. A dançarina tem um microfone nas mãos, porém, não esboça qualquer movimento que simule o canto, o que remete a um desejo irrealizável de expressão e, conseqüentemente, ao anterior estado de coma do qual Alicia se libertou.

A linguagem corporal expressa através da dança, mais uma vez, é um recurso que explicita o papel da personagem no filme. Tal qual a bailarina do espetáculo, cujo corpo é manipulado por mãos masculinas, Alicia é a mulher utópica, a figura idealizada, muda, à absoluta disposição do olhar e do desejo masculino heterossexual. Sua imobilidade e mudez são ideais não só à satisfação sexual, mas também à possibilidade de comunicação entre os sexos. Alicia é o interlocutor perfeito, a figura que pode ouvir os mais recônditos segredos, sigilosamente, e reagir às revelações conforme a ótica daquele que se desnuda.

Nos momentos finais de Fogo, vários casais dançam harmoniosamente em meio a um cenário idílico. Um dos casais desloca-se para um recanto, insinuando um encontro mais íntimo, interditado aos espectadores. Neste momento, Marco e Alicia se olham e surge um letreiro com os seus nomes. É a metalinguagem a serviço de um desdobramento futuro, exterior à narrativa $e$ ao qual, nós, espectadores, não acompanharemos. Temos apenas a certeza de que um novo amor começa e fantasiamos para que este, enfim, seja feliz.

É sob o signo da esperança que Pedro Almodóvar encerra esta história de amor marcada pelo silêncio. É exatamente a falta de palavras e ações que faz da metalinguagem um recurso tão necessário, capaz de diminuir a hegemonia da palavra. Ao espectador, depois de acompanhar histórias de amor marcadas pela tragédia e pelo castigo, fica a certeza de que uma nova relação começa, o que faz do filme "uma ode à vida quando 
Renata de Felippe

recoloca frente a frente um homem e uma mulher recomeçando uma vez mais e sempre, a recriação do mundo". ${ }^{11}$ Sem palavras.

${ }^{11}$ LOEB, Silvia. O impossível... Op. cit. 